\title{
Comparative analysis of data from pumping tests in an unconfined aquifer
}

E. W. BRAND

Mr P. Johnson, Civil Engineering Department, University of Newcastle upon Tyne In his Paper, Dr Brand makes only one brief mention of the possible occurrence of river recharge into an unconfined aquifer brought about by pumping of groundwater from the aquifer. He doubtless considered this possibility during the analysis of data from the City of Antwerp, and I would therefore ask how he concludes that the River Schelde did not influence water levels during borehole observations? Perhaps the estimated radii of influence of the pumped wells were much less than the wells' distances from the river? (The linear scale of Fig. 1 was not given.)

54. Delayed yield as defined by Dr Brand, and boundary recharge of a river, during unsteady state conditions of pumping from an unconfined aquifer, would seem to produce similar effects on water level observations. Perhaps, therefore, Dr Brand, in his answer to my first question, could also show a method whereby these two complementary effects are differentiated in an analysis of pumping test data? If he can explain this as lucidly as he described the Boulton analysis I would be most grateful.

Mr J. F. Peck, Civil Engineering Department, Loughborough University of Technology

This Paper is of considerable interest as reliable tests on cones of depression are very limited. While the results of the equilibrium analyses of the pumping tests shown in Fig. 7 from $r=10$ to $100 \mathrm{~m}$ appear to satisfy the equation for drawdown

$$
H-h=\frac{q}{\pi k(H+h)} \log _{\theta} \frac{R}{r}
$$

this agreement does not hold when $r$ is reduced to the radius of the pump well, $r_{\mathrm{W}}=19 \mathrm{~cm}$.

56. For example, taking the information given in Tables 1 and 2 for test $D$ (which appears to be the most consistent) namely: depth of aquifer $H=3375 \mathrm{~cm}$, measured drawdown $H-h=431 \mathrm{~cm}$, hence actual depth of aquifer at the well $h=2944 \mathrm{~cm}$, and $H+h=6319 \mathrm{~cm}$, coefficient of permeability $k=3.7 \times 10^{-3}$, limit of drawdown $R=23000 \mathrm{~cm}$, equilibrium discharge $q=9.3 \mathrm{cu} . \mathrm{m} / \mathrm{h}=2580 \mathrm{cu} . \mathrm{cm} / \mathrm{s}$,

$$
\text { estimated drawdown at well } H-h=\frac{2580 \times 1000 \times 2.3}{3.7 \times 6319} \log _{10} \frac{23000}{19}
$$

$$
=248 \mathrm{~cm}
$$

The measured drawdown $H-h=431 \mathrm{~cm}$.

This would correspond to a permeability coefficient $k=\frac{248}{431} 3.7 \times 10^{-3}=2 \cdot 13 \times 10^{-3}$.

Similarly, for test B taking $k=8.1 \times 10^{-3}, H+h=4778 \mathrm{~cm}$;

estimated drawdown at well radius, $r_{\mathrm{w}}=19 \mathrm{~cm}, H-h=95 \mathrm{~cm}$

measured drawdown at well radius, $r_{\mathrm{w}}=19 \mathrm{~cm}, H-h=356 \mathrm{~cm}$

equivalent permeability coefficient $k=\frac{95}{356} 8 \cdot 1 \times 10^{-3}=2.16 \times 10^{-3}$

Paper published: Proc. Instn civ. Engrs, 1967, 38 (Oct.) 267-284. 
Again, for test $\mathrm{C}$ taking $k=6.2 \times 10^{-3}$ :

estimated drawdown at well radius, $r_{\mathrm{w}}=19 \mathrm{~cm}, H-h=196 \mathrm{~cm}$

measured drawdown at well radius, $r_{\mathrm{w}}=19 \mathrm{~cm}, H-h=596 \mathrm{~cm}$

equivalent permeability coefficient $k=\frac{196}{596} 6.2 \times 10^{-3}=2 \cdot 04 \times 10^{-3}$

57. From the above, it appears that to estimate the actual drawdown at the well of radius $r_{\mathrm{w}}=19 \mathrm{~cm}$, an approximate value of $k=2 \cdot 10$ would satisfy tests $\mathrm{B}, \mathrm{C}$ and D although the values of $k$ from Fig. 7 are vastly different.

58. This points to a hardened shell around the borehole, probably due to consolidation when boring the pumping wells, although the Author indicated that a special wash-boring method was adopted to avoid this.

59. Alternatively, it may be due to precipitation of some deposit which would progressively close the pores of the sand aquifers resulting in a gradual reduction of the permeability coefficient $k$ thereby reducing the effectiveness of the proposed drainage system, which depends on the discharge from the pumping wells.

60. I should, therefore, be pleased if the Author could offer an explanation of this anomaly, as the differences between the estimated and the measured drawdown heads are very considerable. It would also be interesting to know whether the water discharged by the pumps contained any appreciable sediment and if so some indication of its quantity and nature.

\section{Mr R. F. Stoner, Sir M. MacDonald \& Partners}

This Paper is very useful because it brings together the various methods of analysing pumping test data, applies them to four pumping tests and produces consistent results for permeability. The Author's conclusions conform, in general, with those reached in the Lower Indus Report ${ }^{10}$ which gives detailed analyses of over 80 well pumping tests carried out over a period of six years. The Boulton analyses only became available when the programme was well advanced, but it explained a number of anomalies and was used for about half of the tests.

62. Nearly all of the Lower Indus wells were unconfined, but some more nearly conformed with the 'leaky aquifer' concept. Most of them were partially penetrating wells in that the aquifer was generally much deeper than it was necessary or desirable to go with wells. Most of the wells were $200-300 \mathrm{ft}$ deep whereas the sand aquifer was often greater than $1000 \mathrm{ft}$ deep; the exact location of the basement over much of the area is still unknown. Well discharges generally varied from 1 to $4 \mathrm{cu}$. $\mathrm{ft} / \mathrm{s}$.

63. From the Author's description, it is difficult to determine the relative positioning of the lower ends of the observation wells vis-à-vis the pumping well. For the best results, these should record the point piezometric pressure on a substantially horizontal streamline and, in the fully penetrating case, the observation well should also be fully penetrating. For the partially penetrating case, the observation well should terminate approximately at the depth of the mid-point of the screened portion of the pumping well. With the deeper wells used in Pakistan, observation pipes were carried to a distance of some $2000 \mathrm{ft}$ from the well, spaced approximately at logarithmic intervals. Usually eight or nine were used. The importance of developing and testing the observation wells before starting the pumping test cannot be overstated. Testing consists of pouring water into the wells and making sure that it disappears at a roughly uniform rate in all wells. The $20 \mathrm{~cm}$ diameter of the Antwerp observation wells seems excessive; 2 in. galvanized pipes perforated over the bottom $5 \mathrm{ft}$ were used in the Lower Indus investigations. It is not at all clear from the Paper how the discharge of the pumping well was measured. Various methods were tried in Pakistan and it was concluded that the orifice plate method was the most satisfactory.

64. The Author's analyses agree with the Lower Indus Report findings particularly in regard to the calculation of the coefficient of permeability, but clearly the question 
of the storage coefficient requires further consideration. Boulton's delayed storage concept explained the apparent increase in storage coefficient with increasing pumping time. During early pumping the well behaves in an artesian fashion and the storage coefficient is appropriate to this condition. Delayed yield gives a recharge effect and the time/drawdown plot breaks away from the initial Theis curve. Eventually, the delayed yield reaches a maximum and the time/drawdown plot then follows a second Theis curve. The delayed storage coefficient calculated from this curve is equal to the specific yield of the formation material. It is the delayed storage coefficient that should be used for computations concerning drainage in a well field, particularly where the source of recharge is largely vertical as in aquifers underlying irrigated or rain fed land. A plot of drawdown against $r^{2} / t$ for a Lower Indus Project well is shown in Fig. 15 which demonstrates the typical Boulton condition. A phenomenon that arose from the investigations and was also observed by Boulton

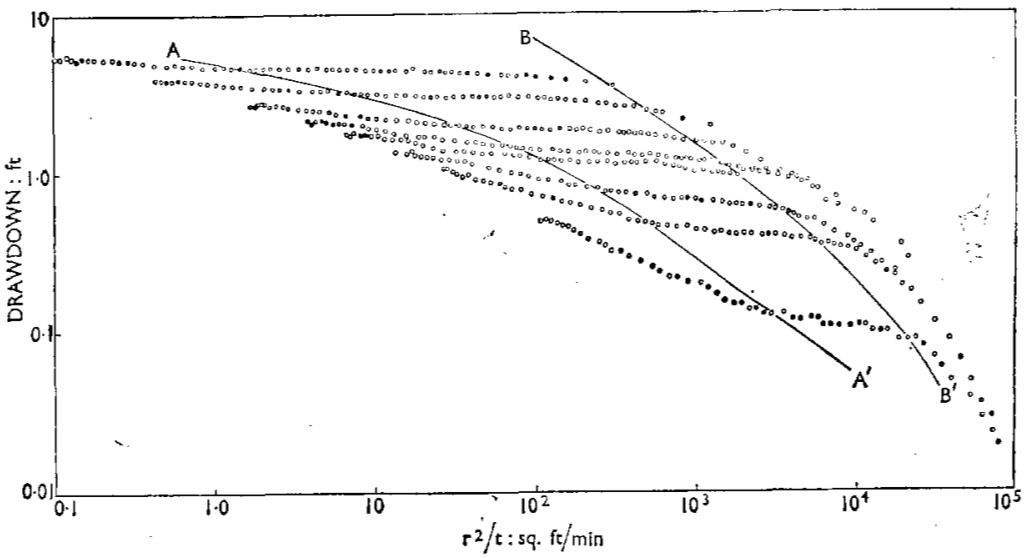

Fig. 15. Graph of drawdown plotted against $r^{2} / t$ for tube well R.N.10

is the apparent variation in storage coefficient with increasing distance from the pumping well. As yet the phenomenon is unexplained.

65. It appears that values for $S^{\prime}$ in Tests $\mathrm{C}$ and $\mathrm{D}$ are somewhat low and it is possible that the assumption that $\eta$ is infinite does not hold in these cases. In Pakistan, we found that $\eta$ should be greater than about 40 before it can safely be assumed to be infinite. Type curves for $\eta$ equal to $6 \cdot 5,10,20$ and 34 have been published ${ }^{11}$ and the use of these may bring $S^{\prime}$ closer to the specific yield of the formation material.

66. Another method of estimating the late time storage coefficient is due to Bennett ${ }^{12}$ and involves calculating the volume of the cone of depression during pumping. Generally, additional shallow observation holes are required for this purpose and these were employed in a number of Lower Indus wells. The volume is calculated from the semilog distance/drawdown plot for several times greater than $1000 \mathrm{~min}$. These values are plotted against the volume of water discharged by the well during the corresponding times of pumping. The resulting graph should be linear with its slope equal to the specific yield of the aquifer material in the watertable zone.

67. The results from the shallow and deep observation wells can also be used to determine the vertical permeability of the aquifer which may be between 10 and 100 
times less than the horizontal permeability for Indus alluvium. It would be interesting to know whether the Author considered measuring anisotropy: perhaps it is considered unimportant for the application in Antwerp.

\section{Professor N. S. Boulton, University of Sheffield}

The pumping test investigation described by the Author is a significant contribution to our understanding of the effect of pumping in unconfined aquifers. The physical conditions in actual aquifers are rarely, if ever, the same as those assumed in simplified mathematical models. Field studies are therefore essential if predictions from theory or analogue experiments are to be correctly interpreted.

69. The Author's discussion of the theoretical methods used calls for comment. The distinction between 'simple' and 'sophisticated' methods of analysis is unimportant to the engineer-hydrologist who is not concerned with the formal mathematics once the functions have been tabulated and plotted as curves.

70. The coefficient of storage can vary in a time/drawdown test by a factor of $10^{3}$, as previous tests have shown. Hence a method of allowing for this large variation is necessary. The delayed yield analysis is a natural extension of equation (3), on which the Theis solution is based, to allow for a variable storage coefficient. The slightly more complicated analysis arises from the need to introduce two additional parameters.

71. The first four methods of analysis listed in Table 2 give no indication whatever of the coefficient of storage $S^{\prime}$ (specific yield) for water-table conditions; hence the justification for the delayed yield analysis leading to the values of $S^{\prime}$ in $\S 42$.

72. All the values of the coefficient of storage in Table 2 are two or three orders of magnitude less than typical specific yield values for unconfined aquifers, which clearly indicates the influence of delayed yield from storage (or as a possible alternative, leaky artesian aquifer conditions) in these pumping tests.

73. In applying the delayed yield analysis, Figs 12,13 and 14 show that the Author has relied more on the accuracy of the drawdowns during the first few minutes of pumping than on the late-time values. Thus, in Figs 12, 13 and 14, the left-hand portions of the curves fit the recorded points closely, whereas the right-hand portions slope upwards to the right more steeply than the trend of the points indicated, as the Author recognizes in $\S 49$. This reliance on the early-time values is not justified for the following reasons.

74. During the first few minutes of pumping at a constant rate of discharge $q$, a significant proportion of the discharge comes from lowering the water level in the well, so that the rate of flow from the aquifer into the well is considerably less than $q$. The present writer's calculations show that, for example, after pumping for $60 \mathrm{~s}$ in Test $B$ the observed drawdown of $2 \mathrm{~cm}$ will be more than doubled if the rate of discharge is strictly constant. Correcting the early-time drawdowns for departures from constant discharge, it is found that a different delayed-yield type curve gives the best fit. For example, for test $C$ (Fig. 13) it is found that instead of $r / B=0.6$, a Type A curve for $r / B=0.316$ gives a closer fit to both the early-time and late-time drawdowns. The corresponding value of the permeability $k$ is $6.0 \times 10^{-3} \mathrm{~cm} / \mathrm{s}$ which agrees well with the Dupuit-Thiem value of $6.2 \times 10^{-3} \mathrm{~cm} / \mathrm{s}$.

75. The drawdowns during the first few minutes of pumping might also be unreliable because the permeability varies near the well.

76. The Author remarks in $\$ 49$ that there is little evidence to support the existence of Type B curves in tests B and D (Figs 12 and 14). It would be truer to say that the plotted points on the right of these figures provide no evidence of following a non-equilibrium Theis curve. (The Theis curves shown in Figs 8 and 10 give such small coefficients of storage that they bear no relation to true water-table conditions.)

77. The indications are, especially from Fig. 14, that the water-table is approaching equilibrium, due possibly to downward seepage from the drift material or the influence of other geohydrologic boundaries. Will the Author say if there is any 
other field evidence for this suggestion? If he can also give the grading of the 'moderately fine' sand adjacent to the water table, this might provide additional evidence for or against the occurrence of delayed yield.

78. The Author's conclusion in $\$ 48$ that 'the method of Theis is generally unsatisfactory for the solution of unconfined aquifers ... . should not be understood as discrediting the Theis method in general. It is relevant to note that the Cooper and Jacob and Chow methods have the same basis as the Theis method, the differences being merely a question of technique in their application. The difficulty experienced by the Author in using the Theis type-curve method is largely due to the impossibility of fitting one type curve in tests $\mathrm{B}, \mathrm{C}$ or $\mathrm{D}$ to both the early-time and late-time drawdown points. The present delayed yield method (which is also based on Theis typecurves) enables an early-time and late-time curve to be fitted to the observed drawdowns.

79. Like other investigators, the Author found that the Dupuit-Thiem equilibrium method gives reliable values of the horizontal permeability coefficient. Will he say whether he took the precaution of averaging drawdowns at equal distances on opposite sides of the pumped well?

80. In his account of the non-equilibrium method, the Author does not mention the distance/drawdown application of this method, using observations in a line of wells. This procedure, the advantages of which have been stated by Wenzel ${ }^{9}$ and Walton, ${ }^{13}$ will probably give a reliable value of the coefficient of storage for watertable conditions, if applied for a time $t$ of about $10^{5} \mathrm{~s}$ by which time any large effect of delayed yield will be dissipated.

81. The statement in $\S 19$ that 'as long as the drawdowns are small ... equation (3) also defines the state in an unconfined aquifer to a close approximation' is demonstrably incorrect except for certain limited ranges of $r$ and $t$. A generally applicable solution must be based on the correct boundary equations at the water table and pumped well.

\section{Dr R. Herbert, Civil Engineering Department, University of Birmingham}

Dr Brand has highlighted the divergence in the results that will occur when each of the well known pumping test techniques are used in turn to interpret the same time/ drawdown levels. Each method is based on the same assumption, namely that the flow to the well is everywhere horizontal. The degree to which this assumption applies varies with the siting of the observation wells and the time after the start of pumping. Thus the major differences between the pumping test results can be partly explained as follows.

83. Each of the pumping test analyses require an accurate knowledge of the watertable position with time. However, in unconfined aquifers the true water-table level is difficult to determine for both the steady and non-steady states. The standard method used to determine water-table levels is to take water-level readings in fully penetrating observation wells. These readings can be incorrect for two reasons, (a) the observation well will disturb the normal flow conditions and depress the watertable level around it, and $(b)$ the well will tend to register the average potential with depth down the observation well's length and not the true water-table height. The latter reason is particularly important both near to the well where the potentials vary greatly with depth and also in the initial stages of pumping when the potential distribution is far from a series of vertical lines. (This is the assumption in the analyses used by Dr Brand, i.e. horizontal flow.)

84. Figure 16 illustrates the effect of an observation well on the flow pattern around the pumped well. In Fig. 16, the left-hand side to the section shows the undisturbed equipotential lines and flow pattern, and the right-hand side shows the disturbed flow pattern around the observation well and the incorrectly read watertable height. Thus, it is clear that observation well readings must be treated with 


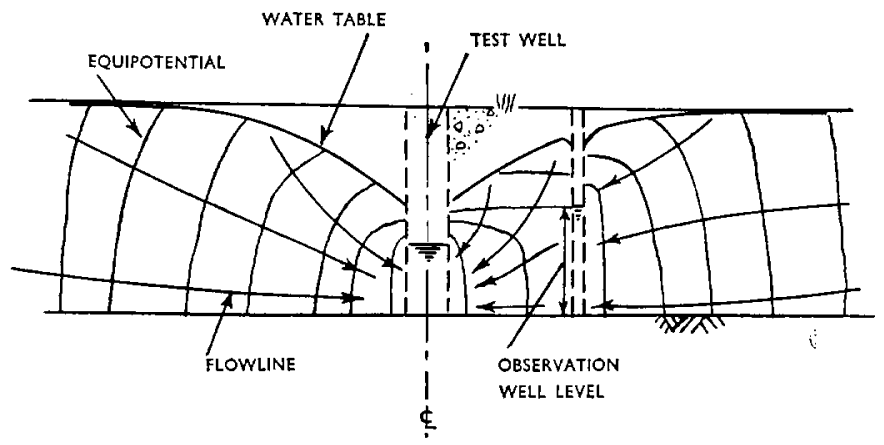

Fig. 16

care if the pumping test analyses are to be accurate since different observation well readings at different radii or times after pumping, when related to the test well, will give different formation constants.

85. For the later stages in the test, observation well readings far from the pumped well will closely correspond to water-table levels and, for this reason, the basic assumption underlying the analysis due to Cooper and Jacob $\left(t / r^{2} \gg S / T\right)$ ensures a more accurate meaningful result.

86. A recent paper by Herbert ${ }^{14}$ describes a new method by which pumping tests can be analysed on resistor meshes; this gives the full potential distribution around the well and does not ignore the vertical component of flow. This method can therefore be used to analyse pumping tests more completely and the following result is taken from the paper ${ }^{14}$ to illustrate the possible inherent errors in observation well readings.

87. A well of radius $6 \cdot 366 \mathrm{ft}$, which fully penetrated an aquifer of depth $1000 \mathrm{ft}$, was pumped at $Q / \pi k=137435 \mathrm{sq}$. $\mathrm{ft}$ with a pumping level of $600 \mathrm{ft}$ above the base of the aquifer. During a time interval of $k t / S_{y}=400$ since the start of pumping the following results were observed. (a) The water table fell gradually from 1000 to $895 \mathrm{ft}$ above the aquifer base at a radius $15.99 \mathrm{ft}$ from the test well's centre. (b) At the same distance from the test well the average potential with depth (the approximate observation well level) fell instantaneously to $754 \cdot 3 \mathrm{ft}$ (this ignores inertia effects) and after $k t / S_{y}=400$ the average potential fell gradually from 754.3 to $715.8 \mathrm{ft}$. Therefore, it is possible that water-table readings taken from an observation well during the early stages of a test could differ by anything up to $895-716 \mathrm{ft}=70 \mathrm{ft}$ and large errors in $k$ and $S_{y}$ values would result.

88. The result described above can also have an effect on the phenomenon of delayed yield from storage. Thus, the inertia of the water, and localized flow into the observation well, would not allow the average head to be registered immediately, i.e., in the problem above the observation well level would not fall instantaneously to $754.3 \mathrm{ft}$ but there would be a time lag. This effect would induce a double curvature in the time/drawdown readings taken from the observation well and therefore might be confused with delayed yield type curves.

89. Thus an alternative method of analysing pumping tests other than by observation well results would be an advantage. The new constant well water level technique due to Boulton, ${ }^{15}$ where only the test well discharge rate need be measured, is an attractive alternative to the more usual methods described in Dr Brand's Paper. Also, the resistor network analysis method mentioned above can be adapted to simulate any type of pumping test accurately and is, at present, being used to carry out research into various aspects of pumping tests at Birmingham University. 


\section{Dr Brand}

I should like to express my gratitude to the contributors to the discussion for their many valuable comments and observations.

91. Mr Johnson observed that no mention was made of the effect of river recharge on the pumping quantities. Naturally, this was considered during the tests but it was thought not to be a significant factor for the non-equilibrium analysis since the pumping well closest to the river (test $\mathrm{A}$ ) was at a distance of about 1.5 kilometres. By comparison, the radius of influence for each test at equilibrium condition was small and can be approximated from Fig. 7; the largest value is $290 \mathrm{~m}$ for test B. Therefore, even after about 30 days of well discharge, the cones of depression did not extend sufficiently far to reach the River Schelde. It was mentioned in the Paper that small stretches of open water still existed in the vicinity of the proposed ring road. Perhaps these acted as geohydrologic boundaries and had some recharging effect on the unconfined aquifer. However, it would be extremely difficult to assess the contribution of these several small sources of recharge and water level indicators gave no reason to suggest that recharge actually occurred.

92. For confined aquifers of finite extent, the well known method of images can be used to assess the boundary recharge effect. This enables the application of the non-equilibrium equation for an infinite aquifer by the introduction of an imaginary well to simulate the effect of a known boundary. ${ }^{18}$ Where delayed yield occurs, as in unconfined aquifers, this technique cannot be employed, except perhaps to the late time-drawdown conditions, and I know of no way in which the effects of boundary recharge and delayed yield can be differentiated. This would seem to be an important topic for future investigation.

93. Mr Peck has illustrated that the drawdowns at the pumping wells were much greater than those predicted from the calculated values of permeability. The washboring procedure, which was carried out by a firm of experts, was adopted to ensure the minimum of soil disturbance in the immediate vicinity of each well and $I$ feel confident that this was achieved. However, the surmise that a hardened shell existed around each well is almost certainly correct for the following reason.

94. As stated in the Paper, the main object of the pumping test programme was to provide information for the design of a permanent dewatering system for a depressed roadway. Over a period of more than a year, many ground water samples were taken in the Antwerp area, including samples from the sites of the four pumping tests. Analyses of these samples by three independent testing laboratories showed the average content of the trivalent ferric-iron $\left(\mathrm{Fe}^{+++}\right.$) to be $12 \mathrm{mg} /$ litre. Extensive laboratory tests at the Sanitary Engineering Laboratory, Delft University, confirmed the site observations that these ions were readily oxidized to give a precipitate of ferric oxide $\left(\mathrm{Fe}_{2} \mathrm{O}_{3}\right)$ which immediately combined with water to form a reddish-brown complex containing 90 to $98 \%$ of water. Therefore, this gelatinous precipitate was certain to have formed anywhere at the pumping test sites where contact with oxygen occurred and particularly where turbulent conditions existed. I feel certain that rapid blockage occurred in the vicinity of the wells as a result of this precipitation mechanism. Consequently, there is no doubt that, by the end of the 30 day period for which each test was run, the hardened shell had formed and had radically reduced the permeability in the immediate vicinity of the pumping wells. However, the presence of these hardened shells does not affect the formation constants calculated from the test results, since no readings close to the wells were used in the analyses described.

95. The presence of exceptionally high concentrations of oxidizable iron in the ground water presented great difficulties in the design of the permanent dewatering system for the ring road and a very sophisticated configuration was adopted as a result. Details of this sub-surface drainage system are given in another paper. ${ }^{17}$

96. The brief details given by Mr Stoner of the pumping tests carried out for the Lower Indus project are of great interest and it is a pity that the results have not been 
published. I cannot agree with Mr Stoner's remarks about the necessity for deep observation holes. In the present four tests, the observation holes were relatively shallow and never extended to a depth greater than half the thickness of the aquifer; they just penetrated the drawn down water-table. Surely, if drawdowns are small, streamlines are almost horizontal and very little error results from the use of observations taken at shallow depths. In fact, a deep hole records only the average potential at a vertical section, while surface potential is more accurately determined by a hole which extends just into the regime of flow. The work in progress at Birmingham University and referred to by Dr Herbert supports this view, it clearly indicates that deep holes are detrimental to the general pattern of flow and could cause considerable inaccuracy in the determination of phreatic levels.

97. Mr Stoner has emphasized the importance of the initial development and testing of observation holes, with which I agree. In Antwerp these were tested in a fashion similar to that employed for the Indus scheme. Pumping well discharges were measured directly by the positive displacement meter, shown in Fig. 3, which was of Belgian manufacture and stated to be accurate within $5 \%$.

98. It is unlikely that the use of delayed yield curves for finite values of $\eta$ would have increased the accuracy of $S^{\prime}$ values for tests $C$ and $D$. Boulton ${ }^{11}$ showed that the probable errors in assuming $\eta$ to be infinite were negligible unless $\eta$ were very small and $r / B$ large; this was not so for any of the Antwerp tests.

99. Professor Boulton's comments and criticisms of the analyses of the test results are well founded, although it should be pointed out that the tests were initially intended to investigate in situ permeabilities rather than to estimate storage coefficients, which were of less importance for the proposed drainage design. For this reason, it is likely that less attention was paid to the merits of the several methods of analysis for the measurement of storage coefficients than was desirable.

100. I agree with the statement by Professor Boulton that the distinction between 'simple' and 'sophisticated' methods of analysis is unimportant to the practising engineer but an attempt was made in the Paper to place considerable emphasis upon the ease of use of the several methods. For example, it was not the intention to discredit the Theis method of analysis but merely to comment upon difficulties experienced in its application. The practising engineer would probably often experience the same difficulties in applying this method as were encountered with the Antwerp observations. For this reason, it is explained in the Paper that Professor Boulton's delayed yield curves give a better fit to the actual time/drawdown results. The slight difficulty experienced in selecting the appropriate delayed yield curve was intended not as a criticism of the method but as an expression of a mechanical disadvantage over analysis by so called 'simple' methods. Perhaps the situation in respect of the use of the delayed yield curves would have been eased if reliance had not been placed upon the early time-drawdown points in Figs 12, 13 and 14. I am grateful to Professor Boulton for pointing out the unjustified use of these early observations which were obtained while the drawdowns at the wells themselves were increasing rapidly but I cannot fully comprehend how the corrections for departures from constant discharge have been made for test $\mathrm{C}$, or how they could be made for tests $B$ and $D$.

101. Without doubt, the influence of delayed yield is shown in the very low storage coefficients quoted in Table 2. It is unlikely that leaky aquifer conditions existed, since the water-table was proved over a very large area before the tests commenced and the Boomse clay was found from bore holes to exist in an impervious form to many metres below the sand aquifer. However, it has already been mentioned that surface recharge from open water cannot be as confidently eliminated. The grading limits for the Antwerpian sand are given in Fig. 17: these particle size distribution curves lend support to the suggestion of the occurrence of delayed yield from storage.

102. With reference to the Dupuit-Thiem equilibrium method, drawdowns were 


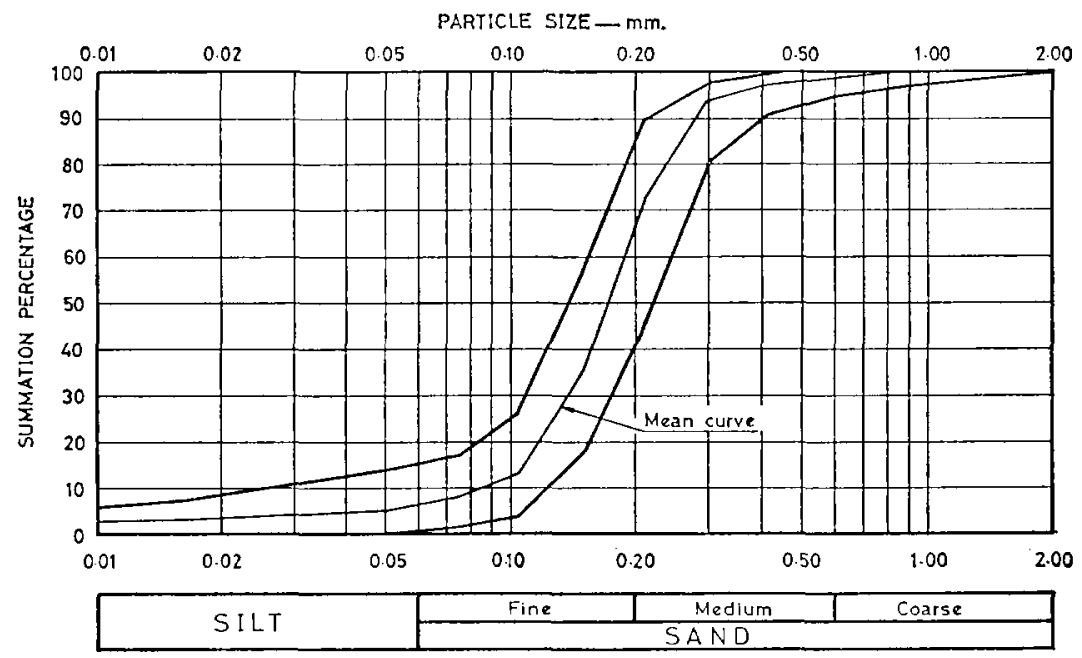

Fig. 17. Range of particle size distribution curves for the Antwerpian sand

not averaged at equal distances on opposite sides of the pumped wells but in Fig. 7 are plotted the drawdowns measured at all points where observation holes were available. Consequently, the straight lines are shown as the best fits to results obtained from locations all around each pumped well: this is evident by a comparison of Fig. 7 with Fig. 2 for test D.

103. Distance/drawdown applications for non-equilibrium analysis were not mentioned because they were thought to have no particular advantage over time/ drawdown methods now that the delayed yield analysis is available. Unfortunately it is now impossible to present results in this form because, as can be seen from Table 1, the discharge from each well was not kept constant for the whole test period and it was continually varied after the initial non-equilibrium results had been obtained.

104. Dr Herbert has expanded on a most important aspect of pumping tests in unconfined aquifers which is often ignored, namely, the possible errors resulting from the measurement of phreatic levels by the conventional method of the use of observation holes. Two examples are given of the effect of disturbances of the normal flow pattern by these holes, both of which were obtained using electrical analogue techniques: alarming inaccuracies are shown to result in water-table observations. However, I feel that both these examples are so extreme that little useful information can be gained from them. For example, no one would use an observation hole only $16 \mathrm{ft}$ from a $12 \mathrm{ft}$ dia. pumping well with a drawdown of $400 \mathrm{ft}$ in an aquifer of depth $1000 \mathrm{ft}$. Whilst Dr Herbert has demonstrated the undesirable influence of these discontinuities in the aquifer, it is thought unlikely that a major error resulted from this cause in the Antwerp tests, because of the very small drawdowns and the distance of the observation holes from the pumping wells, together with the limited penetration into the flow field mentioned earlier.

105. Dr Herbert's statement that 'For the later stages in the test, observation well readings far from the pumped well will closely correspond to water-table levels' is correct but this is in no way a basic assumption, of the Cooper and Jacob solution. When $t / r^{2} \gg S / T$, the well function W $(u)$ can be reduced to two terms by the neglect 


\section{DISCUSSION}

of those that follow in the series expansion of the exponential integral. This merely renders the Theis method of analysis more convenient to use for limiting values of $t$ and $r$.

106. I agree that Boulton's new method with variable well discharge and constant well drawdown is attractive but this solution was not available when the Antwerp tests were carried out. Also, whereas the use of resistor networks will assist greatly in simulating conditions in real aquifers, these can never replace full-scale pumping tests as the only direct way of investigating the hydrological behaviour of an extensive water-bearing body.

\section{References}

10. LOWER INDUS RePORT. Supporting report, Vol. 6, Groundwater, Hunting Technical Services Ltd, and Sir M. MacDonald \& Partners, West Pakistan Water and Power Development Authority, 1965.

11. Stallman R. W., et al. Discussion on analysis of data from non-equilibrium pumping tests allowing for delayed yield from storage. Proc. Instn civ. Engrs, 1964, 28 (Aug.) 603-610.

12. BenNetT G. D. Specific yield determination. Monograph privately received.

13. Walton W. C. Application and limitation of methods used to analyze pumpingtest data. Wat. Well J., 1960 (Feb.-Mar.).

14. Herbert R. Analysing pumping tests by resistance analogue. Ground Wat., 1968 (Mar.)

15. Boulton N. J. The discharge to a well in an extensive unconfined aquifer with constant pumping level. J. Hydrol., 1965, 3, 124-130.

16. Glover R. E. and Balmer G. G. River depletion resulting from pumping a well near a river. Trans Am. Geophys. Un., 1954, 35, 468-474.

17. Brand E. W. Solution of an unusual subsurface drainage problem. To be published in Proc. Am. Soc. civ. Engrs, Irrigation and Drainage Division, 1968. 